\title{
Experimental Technologies in the Diagnosis and Treatment of COVID-19 in Patients with Comorbidities
}

\author{
Md Shahnoor Amin ${ }^{1}$. Marcin Wozniak ${ }^{2,3}$. Lidija Barbaric ${ }^{1} \cdot$ Shanel Pickard $^{1}$. \\ Rahul S. Yerrabelli ${ }^{1}$. Anton Christensen ${ }^{1}$. Olivia C. Coiado ${ }^{1,4,5}$ (D)
}

Received: 24 August 2020 / Revised: 5 August 2021 / Accepted: 1 September 2021 /

Published online: 15 September 2021

(c) The Author(s), under exclusive licence to Springer Nature Switzerland AG 2021

\begin{abstract}
The COVID-19 pandemic has impacted the whole world and raised concerns about its effects on different human organ systems. Early detection of COVID-19 may significantly increase the rate of survival; thus, it is critical that the disease is detected early. Emerging technologies have been used to prevent, diagnose, and manage COVID-19 among the populace in the USA and globally. Numerous studies have revealed the growing implementation of novel engineered systems during the intervention at various points of the disease's pathogenesis, especially as it relates to comorbidities and complications related to cardiovascular and respiratory organ systems. In this review, we provide a succinct, but extensive, review of the pathogenesis of COVID-19, particularly as it relates to angiotensin-converting enzyme 2 (ACE2) as a viral entry point. This is followed by a comprehensive analysis of cardiovascular and respiratory comorbidities of COVID-19 and novel technologies that are used to diagnose and manage hospitalized patients. Continuous cardiorespiratory monitoring systems, novel machine learning algorithms for rapidly triaging patients, various imaging modalities, wearable immunosensors, hotspot tracking systems, and other emerging technologies are reviewed. COVID-19 effects on the immune system, associated inflammatory biomarkers, and innovative therapies are also assessed. Finally, with emphasis on the impact of wearable and non-wearable systems, this review highlights future technologies that could help diagnose, monitor, and mitigate disease progression. Technologies that account for an individual's health conditions, comorbidities, and even socioeconomic factors can drastically reduce the high mortality seen among many COVID-19 patients, primarily via disease prevention, early detection, and pertinent management.
\end{abstract}

Keywords Cardiovascular · Pulmonary · Immune system · Wearables · Nonwearables $\cdot$ Innovation

Olivia C. Coiado

coiado@illinois.edu

Extended author information available on the last page of the article 


\section{Introduction}

COVID-19 has over 125 million confirmed infections worldwide, with over 2.75 million deaths, as of March 26, 2021 [1]. The rapidly progressive disease is caused by the strain severe acute respiratory syndrome coronavirus 2 (SARSCoV-2), which is likely to originate from the populous Huanan Seafood Wholesale Market in Wuhan, Hubei Province of China [2-4]. However, COVID-19 is not the first coronavirus strain to emerge quickly and severely. The first coronavirus outbreak, named severe acute respiratory syndrome coronavirus (SARS$\mathrm{CoV}$ ), occurred in the Guangdong Province of China during 2002-2003 [3, 5]. Ten years later, a second novel strain, Middle East respiratory syndrome coronavirus (MERS-CoV) first emerged on the Arabian Peninsula [6]. This strain has periodically resurfaced, causing outbreaks across several nations in the Middle East and Europe [6]. Initially, COVID-19 was deemed primarily to be a respiratory disease. However, it can affect various organ systems; the severity of the disease strongly depends on the patient's preexisting health conditions and comorbidities. The exact transmissibility of SARS-CoV-2 is not known. However, early estimates of the first reproduction number (R0) vary between 2 and 3 [2]. Personto-person transmission can occur via respiratory droplets or close contact with infected persons, and with approximately $50 \%$ of patients being asymptomatic, the virus can readily spread unknowingly [7]. Additionally, coronaviruses can undergo rapid mutation and recombination [3].

Several research groups have investigated mechanisms by which SARS-CoV-2 may enter the human host around the globe $[8,9]$. These reports indicated that as a first step, the viral surface spike glycoprotein (S protein) attaches to the ACE2, which is highly expressed on pneumocytes (type 2) in the lung, particularly in smokers $[8,9]$. The second step is highly subjected to the host cell proteases, especially the type 2 transmembrane serine protease (TMPRSS2). Studies showed that besides SARS-CoV-2, other coronaviruses and influenza viruses rely on host TMPRSS2 activity during virus entry, including SARS-CoV and influenza H1N (1918 and 2009 influenza pandemics) [10-12]. Multiple scRNA-seq datasets revealed a high expression of human's ACE2 and TMPRSS2 in the nasal goblet and ciliated cells [13]. These work findings may explain why among symptomatic and asymptomatic patients, nasal swabs have yielded higher viral loads than throat swabs [14]. Moreover, this discovery suggested that nasal epithelium may function as a potential primary infection place and a possible source of virions for dissemination among humans [14]. The ACE2 and TMPRSS2 coexpression in other tissues could suggest existing alternative transmission routes already observed clinically (e.g., fecal-oral or nasolacrimal duct transmission) [9, 15]. Recent studies provided new insight into and attempted to explain the high transmissibility of SARS-CoV-2 [14, 16]. Based on the results, SARS-CoV-2 presented more efficient replication in pulmonary cells than SARS-CoV, which can be associated with differences in the amino acid composition of the $\mathrm{S}$ protein (70\% amino acid identity) $[14,16]$. Another study showed a 10- to 20-fold higher binding affinity between SARS-CoV-2 spike protein and human ACE2 compared 
to SARS-CoV [17]. The high receptor-binding ability of SARS-CoV-2 to pulmonary cells may lead to more efficient virus transmission in the general population.

ACE2 is a membrane-bound, counter-regulatory enzyme to ACE, which breaks down angiotensin 2 to angiotensin 1-7, with high levels of ACE2 expressed in the gastrointestinal system, heart, and kidneys [18]. Unlike ACE, ACE2 does not respond directly to ACE inhibitors or angiotensin receptor blockers (ARBs) which usually block the ACE activity or its receptor and are commonly used to treat hypertension. Once the viruses use ACE2 to enter the cell; the ACE2 enzyme is functionally deactivated, which thereby increases circulating levels of angiotensin 2 [19]. Various theories surround the ultimate contribution of ACE2 upregulation seen in patients on antihypertensives to the pathogenesis of SARS-CoV-2. Recent studies made arguments for the possible protective role of ACE2-increasing drugs against COVID-19 [20-23]. Patients on ACE inhibitors have excess free angiotensin 2 that in the setting of viral particles occupying the ACE2 receptor are now enabled to bind the angiotensin 2 receptor type 1 (AT1R) in the lungs, causing increased pulmonary vascular permeability, further mediating the pathology seen in SARS-CoV-2. Figure 1 shows the flowchart of pathogenesis and possible points of interventions. These mechanisms, as well as the contribution of varying ACE2 polymorphisms, are areas currently under investigation [24].

The symptoms and epidemiological factors of COVID-19 can pave the way for the development of novel systems, especially for those with underlying comorbidities, which can better predict, diagnose, and treat the disease. For example, wearable technologies present as an emerging solution to battle COVID-19. As of April 2020, there are approximately 356.8 million users worldwide of wearable technology and 39.1 million users within the USA alone (https://www.statista.com). Many sensors and subsystems (e.g., pulse oximeters, optical heart rate sensors, and 1-lead electrocardiogram) that were previously limited to clinical settings are integrated into such wearable technologies like smartwatches, smart rings, fitness trackers, and cardiorespiratory monitoring patches. In this review article, we (i) summarize the current understanding of SARS-CoV-2 pathogenesis, highlighting the essential comorbidities and organ systems involved; (ii) present examples of developing research to detect early stages of disease based on pulmonary, cardiovascular, and immunologic factors using wearable and non-wearable technology; and (iii) outline the next steps for future diagnosis and disease monitoring that could potentially mitigate disease spread, secondary complications, and mortality.

\subsection{Literature Search Strategy}

References for this narrative review were established with four search engines (PubMed, Scopus, Web of Science, and medRxiv) with listed keywords: COVID-19 pandemic, COVID-19 epidemiology, emerging technologies, wearables, nonwearable, artificial intelligence, machine learning, 3D printing. The literature covered the period from January 2020 to March 2021. This review includes articles published only in English. 


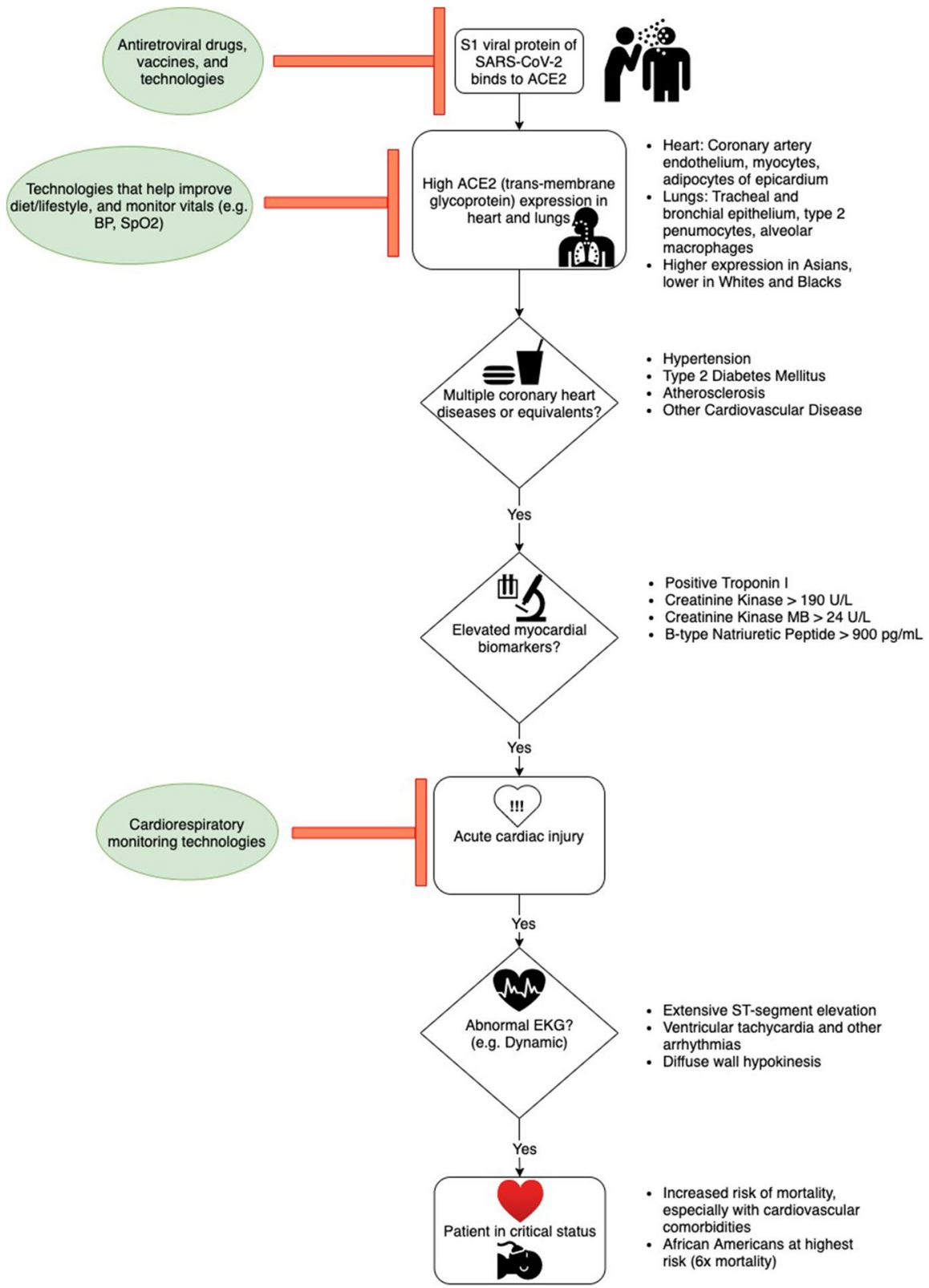

Fig. 1 Proposed flowchart of ACE2, acute cardiovascular disease progression, and potential interventional stages

Methodology: A total of $\sim 500$ papers were pre-identified in the initial search, a total of 6 people screened $\sim 250$ papers and they worked in teams of 2 ; they divided the papers by topics of interest, e.g., cardiovascular, respiratory, and immune 
system. Fleiss' Kappa was used to measure the agreement between the two raters ( 0 indicates no agreement and 1 indicates perfect inter-rater agreement); a Kappa of $>0.61$ was used (good agreement) as a decision factor to include a paper. A total of 120 papers were included in the final version of this literature review.

\section{COVID-19 and the Cardiovascular System}

Cardiovascular disease is emerging as a comorbidity in SARS-CoV-2, and it was previously associated with SARS-CoV and Middle East respiratory syndrome (MERS) pathogenesis. When considering the one study that aimed to identify early disease features for better triage of COVID-19-positive patients, it showed that hypertension $(56.6 \%$,) was the most common feature among the 5700 patients admitted to the hospital, followed by obesity (41.7\%) and diabetes (33.8\%) [25]. However, this study showed the high prevalence of hypertensive patients to be on angiotensin-converting enzyme inhibitors (ACEi) or angiotensin receptor blockers (ARBs), which was associated with higher mortality. The mortality rate among the hypertensive patients was $26.7 \%$ for patients not taking an ACEi or ARBs, 32.7\% for patients taking an ACEi, and 30.6\% for patients taking an ARB [25]. One review study that investigated the effect of preexisting hypertension on mortality showed a range of hazard ratios ranging from 1.7 to 3.05 [26], indicating a possible increase in mortality rate among hypertensive patients. However, these studies did not adjust for potential confounders [27].

Richardson et al. reported presenting symptoms at triage included fever $(30.7 \%)$ respiratory rate above 24 breaths/min (17.3\%), tachycardia (43.1\%), and for some, elevated troponin levels (22.6\%) indicating underlying myocardial injury [25]. In a study of COVID-19 hospitalized patients, $15 \%$ progressed to having fatal pneumonia, while $6 \%$ were in intensive care, especially those older than 60 with hypertension, diabetes mellitus, cardiovascular disease, and other underlying comorbidities [2]. The data pointed out the potential of poorer outcomes of patients with preexisting hypertension, especially in hypertensive elderly patients who will have the compounded risk of cardiovascular disease and age [2,4]. The mortality in patients with cardiovascular diseases (CVD) and normal troponin $\mathrm{T}$ test (TnT) versus patients with CVD and elevated TnT showed to be $13.3 \%$ and $69.4 \%$, respectively [28]. The prevalence of the underlying cardiovascular disease in individuals with SARS-CoV, MERS, and SARS-CoV-2 is $10 \%, 30 \%$, and up to $40 \%$ in hospitalized COVID-19 patients [3].

Inflammatory burden is linked to SARS-CoV-2, potentially leading to myocarditis, arrhythmias, and especially in patients with underlying cardiovascular disease, destabilization of coronary plaques, and aggravated hypoxia [28]. The SARS-CoV-2 myocardial injury mechanism is still under investigation, although early reports pointed to the possibility of both direct myocardial damage mediated by ACE2, as well as injury secondary to inflammatory processes including cytokine storm and secondary hemophagocytic lymphohistiocytosis [28, 29]. The cytokine storm could be mediated by an abnormal response from type 1 and type 2 helper T cells [30], 
and the mechanisms of cardiac injury and inflammatory response could be potentially correlated.

Zhou et al. [31] showed that the human cardiac troponin I (hc-TnI) level was not only lower in COVID-19 survivors following symptom onset, but it remained stable throughout treatment while COVID-19 non-survivors showed marked upward trends of up to $290.6 \mathrm{pg} / \mathrm{mL}$ by day 22 from the onset of illness. Moreover, the troponin rise observed with an increase in inflammatory plasma markers, including D-dimer, ferritin, IL-6, and lactate dehydrogenase [31]. This may indicate that systemic inflammatory changes contribute to disease more so than the myocardial injury alone [29]. However, as evidenced by cases of myocarditis or stress cardiomyopathy due to COVID-19 without coinciding inflammatory signs, a second postulate is that the virus damages the heart via direct injury without much contribution from systemic inflammation [29, 32].

While the overwhelming majority of patients presented with fever, malaise, dry cough, and dyspnea, there have been reports of individuals presenting with predominantly cardiac symptoms, suggesting a different illness pattern [29]. These patients may present with chest pain and ST-segment elevation in the absence of coronary obstruction. Microvascular inflammation and subsequent dysfunction, contributing to myocardial infarction with non-obstructive coronary arteries (MINOCA), could be a result of pericyte infection with the virus [33]. Similarly, some COVID-19 patients, including those previously healthy without the preexisting cardiac disease, have developed fulminant myocarditis via direct viral insult to the heart [29]. A subset of patients in China presented with palpitations and chest pain rather than the common fever and cough [34]. There are also instances of patients presenting with chest pain and cough in the setting of heart failure, cardiogenic shock or in the background of heart transplantation with the concomitant abnormal electrocardiogram (ECG) and echo findings in addition to the hallmark COVID-19 lung opacities [35].

According to Shi et al., patients with cardiac injury showed higher median leukocyte counts, CRP, procalcitonin, CK-MB, myohemoglobin, and hs-TNI [36]. In this study, $28 \%$ of patients with a cardiac injury received an ECG at the time of their cardiac biomarker elevations; 14 patients had abnormal results, including ischemia, T-wave depression and inversion, and ST-segment elevation and Q waves. In this same study of 416 patients, only 14 (3.4\%) presented with chest pain. The mortality rate was found to be higher among patients with cardiac injury (51.2\%), and it increased in association with elevated hs-TNI [36]. He et al. investigated the ECG manifestations in COVID-19 patients and found varying degrees of heart block (e.g., Mobitz type I, right bundle branch block) [37]. The extensive ST-segment elevations seen in inferior leads and leads V1-V4 of the ECG indicated more than just one coronary artery, suggesting a more diffuse myocardial injury like acute myocarditis [37]. Furthermore, several hospitalized COVID-19 patients experienced arrhythmias that changed from one type to another (i.e., dynamic), which resulted in a poorer prognosis [37]. Patients with cardiac injury possessed higher white cell count but a lower number of lymphocytes. A study of 41 admitted individuals with COVID-19 revealed ARDS (29\%), viremia (15\%), and acute cardiac injury (12\%) to be among the most common complications [3]. Wang et al. found that among the $26.1 \%$ of transfers to the ICU for complications, 44\% were due to arrhythmias [38]. 
Disseminated intravascular coagulation (DIC) and pulmonary embolism have gained clinical prevalence with DIC observed in $71.4 \%$ of survivors [33, 39]. The rise of a potential new Kawasaki-like disease in children related to COVID-19 has additional cardiovascular implications. A group in Italy documented ten cases of this child-afflicting vasculitis during their pandemic's peak, reflecting a monthly incidence 30 -fold higher than the previous 5 years [40, 41]. Among those ten children, five presented with fewer classic Kawasaki findings. Additionally, the study showed a high proportion of shock and more than the usual requirement of high-dose corticosteroids to treat the illness, which usually subsides with intravenous immunoglobulin [40, 41].

Historical data showed that more patients die of cardiovascular-related complications than of pneumonia-influenza causes in most influenza epidemics [42]. Inflammatory infiltrates on autopsy were associated with regions of cardiomyocyte necrosis; however, thus far, the presence of SARS-CoV-2 within myocardial tissue is yet to be investigated [43].

\subsection{Early Detection Technologies}

Reliable continuous cardiorespiratory monitoring systems represent a promising frontier in addressing cardiopulmonary demise, especially now considering the rapid deterioration of COVID-19 patients. Several wearable devices have emerged in efforts to downsize the gold standard ECG for non-invasive assessment of CVD, and to digitize cardiac pathology detection, thus replacing the human-factor-dependent stethoscope with PCG (phonocardiogram) and similar technologies. Many sensors for measuring respiratory function involve obtrusive devices such as face masks or nasal cannula pressure monitors. A novel approach engineered by Klum et al. combines single-lead ECG, PCG, and impedance pneumography into a 55-mm wearable device, termed the "multimodal patch stethoscope" [44]. The impedance pneumograph measures the respiratory volume and rate via a relationship between respiratory depth and thoracic impedance change. This technology could be an alternative approach for early diagnosis of COVID-19.

Shahshahani et al. utilized a single sensor for cardiac and respiratory monitoring via a different modality_ultrasounds by way of a PZT-4 piezo transducer [45]. The monitoring of cardiac changes is not limited to ECG or ultrasound, seismocardiography (SCG) also provides increased sensitivity for detecting anatomic and physiologic coronary artery disease. The technique records chest wall vibrations in response to blood flow through vessels as it corresponds to each heartbeat. The SCG has re-emerged for study with recent advances in signal processing to increase clinical utility [46]. The wearable by Inan et al. employs SCG in combination with graph mining techniques to analyze cardiac response in the setting of exercise to detect heart failure [47].

Strategies that interrogate cardiovascular disease from the standpoint of hypertension include the first wrist-worn blood pressure monitor released in 2019 by Omron Corporation (https://omronhealthcare.com/), cleared by the Food and Drug Administration (FDA) and last year put into clinical trials [48]. The 
company additionally has blood pressure and ECG combination devices in their product development pipeline. Wearables such as these, similar to the familiar Holter monitor, could provide meaningful long-term data for measuring hypertensive changes. Currently valued at $\$ 500$, one must consider the ease with which many of those suffering from hypertension will be able to ascertain such products.

Point-of-care diagnostics is another area of great potential for combating disease in multiple realms, including cardiovascular disease. Cardiac troponin remains the biomarker of choice for detecting myocardial injury. Highly sensitive tests were first introduced in Europe in 2010 and are now becoming available in the USA, providing higher precision and lower limits of detection [49]. The hope is to someday detect myocardial injury with the same ease as diabetics measure blood glucose. The Abbott iSTAT® (https://www.pointofcare.abbott/), for instance, has been tested among groups including emergency medical services (EMS) teams within the last 2 years for validity and usability, with generally promising results $[50,51]$.

Public health departments of countries around the world are attempting various methods to control COVID-19 infectivity among the populace via digital surveillance through smartphone software [52]. There are two approaches to digital smartphone surveillance: a centralized approach where location history and personal information may be obtained, sometimes without the user's consent, and a decentralized approach where users are informed of proximity (not exact location) to infected individuals and consent needs to be obtained in order to share personal information with the government [52]. East Asian (e.g., China, Taiwan, South Korea) and some European countries (e.g., Italy, France, UK) favor the former centralized approach for COVID-19 digital tracing, whereas Austria, Germany, and Switzerland favor the decentralized, more private approach. Within the USA, both Apple and Google have collaborated to provide a decentralized approach within their iOS and Android software ecosystems, respectively, but the federal government does not favor a nationwide policy yet [52]. Digital tracing is not meant to replace traditional infection prevention measures such as physical distancing, wearing masks in public, regular testing, and isolation/quarantine, but rather to complement such practices [52]. Besides digital surveillance, various other applications exist to educate users and health professionals regarding preventive and behavioral measures, and methods of self-isolation [53]. In one study of 52 smartphone apps in Brazil, 76.9\% were for Apple iOS, 15.4\% for Google Android, and $7.7 \%$ were available for both platforms [53]. This was observed to be an effective means of educating the public about COVID-19, especially since up to $90.4 \%$ of Brazilian households relied on smartphones as their primary means of accessing the Internet [53]. Prolonged isolation can negatively impact mental health, especially among the geriatric population ( $>65$ years), who are also the most susceptible to COVID-19. To mitigate mental illnesses, mobile technologies can help older adults stay connected to family/friends (e.g., FaceTime, Skype) and obtain meal delivery services. With the expansion of Medicare reimbursement policies to include telehealth by the Centers for Medicare \& Medicaid Services, older adults can now continue to remotely receive medical care for chronic conditions [54]. 


\section{COVID-19 Effects on the Pulmonary System}

Clinical features related to patients with COVID-19 differ among individuals, but the majority present a mild form of respiratory illness with no or flu-like symptoms (e.g., dry cough, fever, and fatigue). Other symptoms may include sore throat, headache, joint pain, anosmia, nausea, and diarrhea $[14,15,55,56]$.

People suffering from chronic obstructive pulmonary disease (COPD) have a high risk of morbidity and mortality due to pneumonia [57]. Regarding COVID19, COPD patients showed an elevation in the ACE2 levels [58, 59]. Based on results presented in the meta-analysis, COPD is associated with an over five-fold increased risk of severe COVID-19 infection [60]. This study showed that patients suffering from COPD should follow more restrictive actions for minimizing potential exposure to SARS-CoV-2. Other studies indicate that smoking is associated with increased risks of severe COVID-19 infection [61, 62]. Data shows that smoking individuals have a 1.4 times higher risk of severe COVID-19 symptoms, and 2.4 times more often require mechanical ventilation or die than non-smokers [63].

Guidelines for SARS-CoV-2 testing are modifying as the disease spreads in the general population. Currently, the Centers for Disease Control and Prevention (CDC) recommends a reverse transcriptase-polymerase chain reaction (RT-PCR) technique to detect COVID-19 cases [64]. According to CDC guidelines, specimens for testing are collected from an upper respiratory swab-nasopharyngeal (N.P.) sample. While RT-PCR testing is considered the gold standard due to its high specificity, it is a very time-consuming and complicated manual process.

\subsection{Imaging Technologies}

Radiography examination has been recently proposed as an alternative screening method for COVID-19 [65, 66]. Early reports demonstrated that patients infected with COVID-19 present characteristic visual abnormalities in chest radiography images that are typical visual indicators of those infected with COVID-19 [67, 68]. To facilitate this process, a group of researchers introduced an open-source deep convolutional neural network invented for the identification of COVID-19 (COVIDNet) cases based on chest X-ray (CXR) image analysis. COVID-Net development may improve the diagnostic and treatment of COVID-19 and lead to deep learning solutions for detecting COVID-19 cases from CXR images [69].

Pneumonia appears to be a more severe form of the disease, leading in severe cases to respiratory failure, acute respiratory distress syndrome (ARDS), and multiorgan failure, and is associated with high mortality in patients infected with SARSCoV-2 [14, 63, 70, 71]. True definitive clinical assessment of ARDS depends on histopathological techniques to determine lung tissue destruction. Once the diagnosis is made, therapy is monitored with a sequential physical exam and current imaging modalities plus pulmonary function tests (PFTs). To continuously sample lung tissue to track repair or destruction over time would be invasive and unfeasible. Bronchiolar lavage as well, though less invasive, does not always yield useful 
results or precisely differentiate between pathological cell profiles. Promising new technology such as intravital probe-based confocal-laser endomicroscopy (pCLE) could provide high-resolution images to enable multiplex screening of proteases and microbes, simultaneously allowing for longitudinal lung monitoring [72]. Commercial catheters ranging from 300 microns to $1.5 \mathrm{~mm}$ containing a bundle of up to 30,000 optical fiber microprobes have been used in the endobronchial approach. Such modalities are ushering-in the promise of alveolaroscopy and optical biopsy, highly sought-after modalities that allow for precision in the care of lung injured patients [72].

Lung ultrasound, specifically ultrasound lung comets (ULCs), is also emerging as a potential technique in ARDS-evaluation. ULCs evaluate the measurement of extravascular water in the lung, which suggests alveolar wall thickening, a prominent feature in the pathogenesis of ARDS [73-75]. While chest radiography may fail to capture ARDS, lung ultrasound tends to miss the detection of pathology at the distant pleura [70]. The use of ultrasound is promising for this purpose, although more data is needed, especially on patients who are not critically ill. While authors suggested that ultrasound should be used complementarily, not in place of chest radiographs, ultrasound possesses significant value for its unique features, ease of use, the omission of radiation, and economic cost [70, 71, 73]. Benefits of these imaging modalities include portability, fast acquisition, innocuity and especially in the case of pCLE, high spatial resolution and penetrance [72].

Nuclear magnetic resonance (NMR) metabolomics addresses the problem above regarding a lack of precision in assessing microbial burden on bronchiolar lavage $[76,77]$. This imaging modality presents another novel approach to delineating prognosis in ARDS, a real clinical challenge with current methods (e.g., bronchiolar lavage, traditional imaging, biopsy). Viswan et al. demonstrated the ability of NMR metabolomics to discriminate between patients with mild, moderate, and severe ARDS using a biomarker model [78]. Though the Berlin criteria currently defines ARDS based on just the patient's oxygen levels, future technologies using imaging or biomarkers could be more informative methods to rapidly assess pulmonary function.

\section{COVID-19 and the Immune System}

While COVID-19 manifests by harming several organ systems, unfolding data suggest that aberrant immune function plays a critical role in the progression of this disease $[79,80]$. The current theory is that a locally triggered immune response involving macrophages and monocytes leads to the cell-mediated response by lymphocytes. In severe cases, a dysregulated response can then lead to systemic pathology. The local response is pro-inflammatory, involving many players such as IL-6, IFN- $\gamma$, MCP1, and IP-10 [79]. Besides, lung deterioration with ground-glass opacities is becoming known as a hallmark [81]. The reasoning behind this may be the pulmonary recruitment of immune cells from the blood and lymphocytic infiltrate into the respiratory system [79]. Furthermore, patients with cardiac injury possessed higher white cell count, but a lower number of lymphocytes [36]. Lymphopenia is 
mostly associated with worse outcomes for COVID-19 patients [31, 82]. Patients with higher levels of troponin and acute phase reactants had concomitantly higher amounts of leukocytes but lower levels of lymphocytes in several studies $[3,34,36]$.

Presepsin (PSP) is a regulatory factor that modulates immune responses by interaction with $\mathrm{T}$ and B lymphocytes. A study involving $69 \mathrm{SARS}-\mathrm{CoV}-2$ patients showed that higher values of PCP were associated with longer ICU stays [83]. PSP has particular value as a prognostic biomarker because of its physiologic pattern of response to pathogens. The host-pathogen interaction results in a dose-response that occurs initially at pathogen recognition and remains elevated for several days based on disease severity [83]. Biomarkers such as PSP that show potential for risk stratification are an ideal basis for technologies that seek to harness immunologic tracking for disease prognosis.

While many individuals can recover via neutralizing antibodies with minimal inflammation and damage, current data estimates severe disease in approximately $14 \%$ of those infected [84]. The ensuing respiratory distress is likely the result of excessive leukocyte and $\mathrm{T}$ cell infiltration, systemic cytokine storm, pulmonary edema and pneumonia, and widespread inflammation and multiorgan damage [79]. A reduction in ACE2 post-infection may contribute to renin-angiotensin system dysfunction, inducing blood pressure, fluid and electrolyte imbalances that further enhance inflammation, and vascular permeability in the respiratory system [79].

Cytokine storm, in particular, mediates lung inflammation and is thus a potential target for emerging immune-sensing technology and immune-targeted systemic therapy [79], and it is implicated in both infectious and non-infectious diseases. The concept of cytokine storm, involving graft-versus-host disease, was developed during the H5N1 avian influenza outbreak of 1993 [85]. Since then, it has been implicated in infectious disease research from Epstein-Barr virus-associated hemophagocytic lymphohistiocytosis to severe acute respiratory syndrome coronavirus in SARS-CoV and now SARS-CoV-2. In severe respiratory infections, the inflammatory markers seen in the peripheral blood more likely represent an even more pervasive immunopathology occurring deep within the respiratory tissues [85]. The process's importance in the context of COVID-19 is highlighted by the FDA's recent approval of a blood purification system [86]. This system combines Terumo BCT's Spectra Optia Apheresis System and specific filters from Marker Therapeutics AG to detoxify COVID-19 patients' blood from the proteins released in a cytokine storm. Groups such as Wear Optimo (https://www.wearoptimo.com/) proposed a micro wearable sensor to monitor IL-6 in the skin interstitium, which could be useful as a sharp peak as this cytokine typically signals an emerging cytokine storm [25]. This marker is low in those with mild symptoms and could provide a basis for the prediction of severe respiratory failure. Additionally, a group at MIT is working on a solution specifically to combat cytokine storm from within the body via injectable water-soluble proteins that mimic the structure of cytokine receptors [87]. Although not explicitly engineered for COVID-19, such solutions could be valuable as the inflammatory component in the disease process of SARS-CoV-2 grows in its importance. 


\section{Future Methods of COVID-19 Diagnosis and Prevention}

Novel approaches to inpatient diagnostics have great potential for addressing the need for more continuous monitoring of heart and lung health at a cellular level while under stress, as in the case of severely ill COVID-19 patients who experience a rapid decline. Onboard health data can be aggregated (i.e., crowdsourcing), compared anonymously in real-time with other users' data, and analyzed using various machine learning algorithms (e.g., predictive analytics) embedded into the device's microprocessor [37].

Presently, detecting new positive COVID-19 cases require RT-PCR, which is labor-intensive and is burdened with the risk of false-negative error. Antibodybased tests have also been introduced on the market, but they heavily suffer from a lack of sensitivity and specificity. For this reason, it is imperative to create new diagnostic techniques allowing for both more accurate and much faster recognition with COVID-19 patients. To overcome those challenges, utilizing artificial intelligence-driven (AI) strategy for developing new diagnosis and treatment approaches has enticed note since the incipience of the COVID-19 pandemic. The outbreak has forged new demands where AI can significantly support physicians regarding diagnosis and treatment and assist the already experiencing difficulty in healthcare facilities.

Artificial intelligence algorithms, using data from all users, can analyze such parameters to help indicate whether the user is "sick" or "not sick," and guide the user on next steps (e.g., go to the emergency department or quarantine at home) [88]. One review study critically assessed 31 prediction models used for diagnosis and prognosis of COVID-19 [89]. Of the 10 prognostic models, the most frequently reported predictors of severe prognosis in COVID-19 patients included demographics (age, sex), specific computerized tomography (C.T.) scan-derived features, and the serum C-reactive protein, lactate dehydrogenase, and lymphocyte count. Other technologies that can be used to diagnose and treat possible COVID-19 include the ability to measure ACE2 plasma activity [90, 91] or ACE2 in the mucosa of the oral cavity as predictors of entry of the virus into the cell to cause the final infection [92].

Machine learning, a subset of AI, has been utilized to develop a more precise diagnosis approach for COVID-19 patients. The algorithm uses 151 peerreviewed studies and focuses on patient symptoms and laboratory test results. The paper reveals a link between male sex and high levels of neutrophils and lymphocytes in blood serum. As claimed by the authors, patients with COVID-19 can be gathered into subgroups according to the immune cells' number in serum and symptoms and gender. Researchers used the XGBoost algorithm, which characterizes with high sensitivity and specificity (92.5\% and 97.9\%, respectively) [93].

In other studies, the COVID-19 has been diagnosed using a machine learning strategy and laboratory blood tests $[94,95]$. Brinati et al. utilized a machine learning approach and hematological information acquired from routine blood sample tests to identify COVID-19 patients [96]. Researchers have proven that the method provides good precision. 
In another study, researchers from Brazil applied a multipurpose machine learning strategy to predict the possibility of occurrence of the critical condition in patients with confirmed SARS-COV2 infection [97]. Scientists used routine, clinical, laboratory, and demographic information to learn five algorithms (extreme gradient boosting, extreme gradient boosting, artificial neural networks, random forests, catboost, and extra trees). Lymphocyte/C-reactive protein and C-reactive protein/ Braden Scale ratio were the most significant for algorithms [97].

Due to the sudden emergence of COVID-19, the first stage of addressing the pandemic involves prevention of even contracting the virus in the first place. In hospital and clinic scenarios, case isolation is performed, identifying close contacts, environmental disinfection, and prompt usage of personal protective equipment (PPE) like face masks and shields [4]. Outside the hospital, the recommendation is to wear face masks, cover coughs/sneezes, apply min. 60\% alcohol-based hand sanitizer, maintain an appropriate distance from others, and avoid touching the eyes, nose, and mouth with unwashed hands [4]. However, the authors do not mention whether wearable (e.g., smartphone-based) or non-wearable technology (e.g., 3D printing) could be used to ensure that people maintain social distancing and improve treatment and diagnosis.

\subsection{Wearable Technologies}

Carefully and precisely tracking emerging hotspots is a critical task for maximizing the efficient use of social distancing and healthcare resources. One approach currently being investigated for tracking the spread of COVID-19 and the emergence of hotspots is through a network of smart thermometers in collaboration with commercial vendors like Kinsa [98]. Kinsa already has 1,000,000+ consumer thermometers in use that report recorded temperatures and geolocation to its cloud service, and anomalies in this data can be used to more closely monitor emerging hotspots. At least one research group is using smartphone-recorded audio of coughs to detect COVID-19 and, in a non-peer-reviewed preprint, is reporting that they can obtain up to $81 \%$ specificity while maintaining $>99 \%$ sensitivity (or can obtain up to $89 \%$ sensitivity while maintaining $>99 \%$ specificity) for detecting COVID-19 on their dataset of COVID-19, pertussis, bronchitis, and healthy coughs [99]. However, generalizability in a prospective clinical trial still needs to be demonstrated [99]. In theory, this technology need not be restricted to use only in a medical center and could be a way for individuals to self-test in isolation. Another wearable technology is the Oura Ring (Oura; https://ouraring.com/), which tracks respiratory rate, body temperature, and heart rate to better detect early signs of COVID-19 infection, deployed in collaboration with University of California, San Francisco.

\subsection{Innovative Non-wearable Technologies}

Three-dimensional (3D) printing is a novel and innovative technology uniquely well-positioned to support challenges arising during the COVID-19 pandemic. 3D printing can be used to produce a tailored seal in N95 respirators masks. The mask 
seal could be customized based on anthropometric data improving its comfort and fit. In a study using personalized mask seal prototypes, subjects showed improved contact pressure compared with commercially available respirator masks [100]. Currently, the FDA, National Institute of Health (NIH) 3D Print Exchange, and the United States Veterans' Association are making efforts to develop a 3D printed N95 mask prototype. It is worth noting that many researchers propose and test numerous face mask designs with variable degrees of success (Copper3D, https://copper3d. com/; Gladius Friends, http://gladius.si/; Lowell Makes, https://lowellmakes.com). It is important to remember that currently, only prototypes of N95 masks developed on 3D printing platforms are available, and local essential testing procedures assessing the quality of personal protective equipment (PPE) may have been modified from previously established N95 testing. Further modifications on PPE include protective surgical face shields securing the user's eyes and mouth. Shields are made of transparent, lightweight biomaterials that provide high optical clarity and can easily be printed using 3D technology [101]. A research group at MIT and Harvard (http:// news.mit.edu/) are currently developing a mask that has embedded sensors which exhibit a fluorescent signal when a person with COVID-19 coughs, sneezes, or even breathes, in an effort to notify surrounding individuals. The group is in early stages of modifying the sensor so it can detect presence of SARS-CoV-2 genome when the user wears the mask and exhales, as a form of rapid detection.

After hospitalization, current diagnostic methods focus on determining the likelihood of a hospitalized patient progressing to ARDS, which is a significant fatal risk factor [88]. Regional shortages of crucial equipment for non-invasive ventilation have been recently observed due to the COVID-19. 3D printing technology can be successfully used to produce single-use ventilator valve sets using available biomaterials. Venturi valves [102], a crucial component of such equipment delivering oxygen at fixed concentrations for patients with ARDS, became difficult to reproduce or substitute during the observed increased demand. This extraordinary situation has successfully developed methods for producing these valves by the engineers at an Italian 3D printing startup [103]. However, manufacturing automated ventilators using 3D printing technology is still a challenge for engineers across the globe. Illinois Rapid-Vent (https://rapidvent.grainger.illinois.edu/) has designed a prototype of the open-source automated ventilator with flow-driven, pressure-controlled respiratory support systems featuring necessary valves and flexible membranes. While $3 \mathrm{D}$-printed ventilators are still a work in progress, the alternative solution currently being applied is the production of 3D-printed ventilator splitters which allows a single ventilator to support multiple patients [104].

To confirm the diagnosis in a patient with suspected infection, RT-PCR helps to detect the nucleic acids of SARS-CoV-2 in the sputum, throat swabs, and lower respiratory tract samples [4]. 3D printing technology can also be implemented to improve the diagnostic process. COVID-19 testing capacity could be potentially increased by supporting manufacturing specimen collection kits with 3D-printed test swabs and it can be made from a flexible biomaterial with the micro-fine customized tip using design software.

It is expected that robust technologies constructed of cost-effective and readily available materials would lead to a more democratized medicine, especially 
considering patients of varying socioeconomic backgrounds. However, at least within the USA, there is increasing disparity in healthcare access and resources between the wealthy and poor, despite progressive improvements in innovative technologies. Within the USA, individuals with the lowest incomes and education have consistently showed to be the least healthy among the populace, especially among both non-Hispanic Whites and Blacks [105]. It is commonplace that those of higher socioeconomic status tend to be early adopters and benefiters from the technologies above, as several studies have shown [106-108]. Importantly, this is not necessarily due to a difference in access but in societal structure and economics that put the disadvantaged often as an after-thought for stakeholders, assuming that benefits of emerging technology will trickle down equally [109].

\subsection{Social Epidemiology and COVID-19 Complications}

Understanding the social epidemiology of COVID-19 can help guide technology development by tailoring to highly susceptible populations, especially for those with increased comorbidities. A lack of data on population-based rates [11, 13] and systematic testing in the USA has led to an inability to draw exact conclusions from the available COVID-19-positive estimates [49]. Individuals of all ages succumbed to severe illness; those 65 and older [110] or with underlying comorbidities were affected the most according to international data [31]. China, Italy, and the USA reported higher death numbers of males [25]. The median age of infected patients in one study was 59 years [4]. As data emerges, several states show that black and Hispanic individuals make up a disproportionately high number of cases and deaths $[111,112]$. The data from New York shows death rates among Blacks (265.0 deaths per 100,000 population as of May 13, 2020) and Hispanic/Latino persons (259.2) were substantially higher than that of Whites (130.3) or Asians (121.8) [113]. Reports within the USA indicate that African Americans are both three times more likely to get infected and six times more likely to die from COVID-19 when compared to American Caucasians [114]. For instance, in severely affected areas like Chicago, Louisiana, and Michigan, Blacks make up between 14 to 35\% of the population but can account for up to 70\% of deaths due to COVID-19 [114]. When considering the root causes of increased risk in these vulnerable populations, several factors have historically contributed to poorer health outcomes. Higher prevalence of associated comorbidities like hypertension, diabetes, body mass index (BMI > 30), and other cardiovascular diseases contribute to this disproportionate impact on Black and Hispanic Americans [3]. Additionally, Black populations are more prone to living in denser metropolitan areas plagued with "food deserts." Lack of proper nutrition and reduced access to healthcare are two factors known to result in increased comorbidities and mortality for Black Americans [114]. Often, Blacks do not occupy jobs that offer "privileges" such as teleworking or social isolation, but rather work in service sector jobs that rarely have the opportunity to maintain social distancing [114]. With the unfortunate combination of increased comorbidities plus adverse social determinants of health, Blacks are disproportionately facing the brunt of COVID-19 infections and mortality within the USA [114]. Taking all 
this into account, any novel technical solution used for early detection and triage of COVID-19 cases should ideally be affordable, accessible, and applicable to susceptible populations [114].

Though a small percentage of the overall cases, COVID-19 can affect children. Of the 1.2 million cases within the pediatric population (age 0 to 17) by the end of 2020, children under four accounted for 7.4\% of cases [115]. By March 2021, the number of pediatric cases rose to nearly 3.34 million across 49 states [116]. Similar to adult populations, ethnic minorities like Hispanics and Blacks were disproportionately affected, accounting for up to $41.3 \%$ of total pediatric cases [115]. In one study of 7480 children, boys and girls were affected almost equally, and presented primarily with fever, chills, and cough, with about $2 \%$ of children admitted to pediatric intensive care units [117]. Overall, COVID-19 appears to be milder in children than adults, likely due to less number of comorbidities at such young ages. In another study of 145 children, patients younger than 5 were observed to have equivalent or increased SARS-CoV-2 nucleic acid in their upper respiratory tract compared with adults or older children [118] However, early school closures within the USA likely thwarted an even higher surge in household cases due to school-age children spreading the virus to household members [115]. Multisystem inflammatory syndrome in children (MIS-C) is a rare condition associated with COVID-19 infection where various internal organs (e.g., heart, lungs, kidneys) incur inflammation, and children may exhibit fever, gastrointestinal upset, and lethargy [119]. In one study of 1116 children, MIS-C cases were more likely between 6 to 12 years of age, and of non-Hispanic Black ethnicity, with over $56 \%$ of patients having some form of cardiorespiratory involvement [120].

\section{Conclusion}

Wearable technology can be extremely helpful in disease prevention by tracking the infection chain, identifying infected patients, and maintaining social distancing (e.g., smartwatches, smart rings, smart thermometers, GPS-enabled fitness trackers). Some cellphone manufacturers have recently implemented contact tracing software within their operating systems, though this may also prompt future research studies into user privacy of technologies in disasters such as pandemics. Other non-wearable technologies could be crucial for drastically reducing the mortality observed among COVID-19 patients with cardiovascular and pulmonary comorbidities, (e.g., AI predictive algorithms, convolutional neural network, 3D printing). Emerging technologies can augment traditional prophylaxis such as social distancing, washing hands, refraining from touching one's face, and wearing face masks in public.

This is the first review study to outline and review preventative, diagnostic, and management technologies used against COVID-19, especially for patients with cardiovascular and pulmonary comorbidities. A flowchart of ACE2, cardiovascular disease progression, and appropriate stages of technological intervention are proposed. Novel cardiorespiratory systems, immunosensors, connected biomedical devices, and other innovations are discussed as points of intervention. This review emphasizes the need to develop future technologies that address patients from different 
socioeconomic backgrounds, since there is an apparent disparity of mortality among different segments of the population. This is especially true since those with adverse social determinants of health are significantly more likely to be infected and die from COVID-19, as highlighted above. Therefore, innovative firms, researchers, and clinicians need to collaborate and develop novel cost-effective, attainable, and rapidly deployable solutions that mitigate the deadly consequences of COVID-19 and account for the socioeconomic disparities among affected populations.

Availability of Data and Material Not applicable.

Code Availability Not applicable.

\section{Declarations}

Conflict of Interest The authors declare that they have no conflict of interest.

\section{References}

1. Johns Hopkins University (2020) COVID-19 Data Center. https://coronavirus.jhu.edu. Accessed 24 Aug 2020

2. Park SE (2020) Epidemiology, virology, and clinical features of severe acute respiratory syndromecoronavirus-2 (SARS-CoV-2; Coronavirus Disease-19). Clin Exp Pediatr 63:119

3. Madjid M, Safavi-Naeini P, Solomon SD, Vardeny O (2020) Potential effects of coronaviruses on the cardiovascular system: a review. JAMA Cardiol. https://doi.org/10.1001/jamacardio.2020.1286

4. Adhikari SP, Meng S, Wu YJ, Mao YP, Ye RX, Wang QZ, Sun C, Sylvia S, Rozelle S, Raat H, Zhou H (2020) Epidemiology, causes, clinical manifestation and diagnosis, prevention and control of coronavirus disease (COVID-19) during the early outbreak period: a scoping review. Infect Dis Poverty 9:29. https://doi.org/10.1186/s40249-020-00646-X

5. Li F, Li W, Farzan M, Harrison SC (2005) Structure of SARS coronavirus spike receptor-binding domain complexed with receptor. Science 309:1864-1868. https://doi.org/10.1126/science.11164 80

6. Hajjar SA, Memish ZA, McIntosh K (2013) Middle East respiratory syndrome coronavirus (MERS-CoV): a perpetual challenge. Ann Saudi Med 33:427-436. https://doi.org/10.5144/02564947.2013.427

7. Levinson W (2016) Review of Medical Microbiology and Immunology, 14th edn. McGraw-Hill Education, New York

8. Guo YR, Cao QD, Hong ZS, Tan YY, Chen SD, Jin HJ, Tan KS, Wang DY, Yan Y (2020) The origin, transmission and clinical therapies on coronavirus disease 2019 (COVID-19) outbreak - an update on the status. Mil Med Res 7:11. https://doi.org/10.1186/s40779-020-00240-0

9. Yan R, Zhang Y, Li Y, Xia L, Guo Y, Zhou Q (2020) Structural basis for the recognition of SARSCoV-2 by full-length human ACE2. Science 367:1444-1448. https://doi.org/10.1126/science. abb2762

10. Chaipan C, Kobasa D, Bertram S, Glowacka I, Steffen I, Tsegaye TS, Takeda M, Bugge TH, Kim S, Park Y, Marzi A, Pohlmann S (2009) Proteolytic activation of the 1918 influenza virus hemagglutinin. J Virol 83:3200-3211. https://doi.org/10.1128/JVI.02205-08

11. Hoffmann M, Kleine-Weber H, Schroeder S, Kruger N, Herrler T, Erichsen S, Schiergens TS, Herrler G, Wu NH, Nitsche A, Muller MA, Drosten C, Pohlmann S (2020) SARS-CoV-2 cell entry depends on ACE2 and TMPRSS2 and is blocked by a clinically proven protease inhibitor. Cell 181:271-280 e278. https://doi.org/10.1016/j.cell.2020.02.052 
12. Matsuyama S, Nagata N, Shirato K, Kawase M, Takeda M, Taguchi F (2010) Efficient activation of the severe acute respiratory syndrome coronavirus spike protein by the transmembrane protease TMPRSS2. J Virol 84:12658-12664. https://doi.org/10.1128/JVI.01542-10

13. Sungnak W, Huang N, Becavin C, Berg M, Queen R, Litvinukova M, Talavera-Lopez C, Maatz H, Reichart D, Sampaziotis F, Worlock KB, Yoshida M, Barnes JL, Network HCALB (2020) SARSCoV-2 entry factors are highly expressed in nasal epithelial cells together with innate immune genes. Nat Med. https://doi.org/10.1038/s41591-020-0868-6

14. Zhou P, Yang XL, Wang XG, Hu B, Zhang L, Zhang W, Si HR, Zhu Y, Li B, Huang CL, Chen HD, Chen J, Luo Y, Guo H, Jiang RD, Liu MQ, Chen Y, Shen XR, Wang X, Zheng XS, Zhao K, Chen QJ, Deng F, Liu LL, Yan B, Zhan FX, Wang YY, Xiao GF, Shi ZL (2020) A pneumonia outbreak associated with a new coronavirus of probable bat origin. Nature 579:270-273. https://doi.org/10. 1038/s41586-020-2012-7

15. Guan WJ, Ni ZY, Hu Y, Liang WH, Ou CQ, He JX, Liu L, Shan H, Lei CL, Hui DSC, Du B, Li LJ, Zeng G, Yuen KY, Chen RC, Tang CL, Wang T, Chen PY, Xiang J, Li SY, Wang JL, Liang ZJ, Peng YX, Wei L, Liu Y, Hu YH, Peng P, Wang JM, Liu JY, Chen Z, Li G, Zheng ZJ, Qiu SQ, Luo J, Ye CJ, Zhu SY, Zhong NS, China Medical Treatment Expert Group for C (2020) Clinical Characteristics of Coronavirus Disease 2019 in China. N Engl J Med 382:1708-1720. https://doi.org/ 10.1056/NEJMoa2002032

16. Chan JF, Kok KH, Zhu Z, Chu H, To KK, Yuan S, Yuen KY (2020) Genomic characterization of the 2019 novel human-pathogenic coronavirus isolated from a patient with atypical pneumonia after visiting Wuhan. Emerg Microbes Infect 9:221-236. https://doi.org/10.1080/22221751.2020. 1719902

17. Wrapp D, Wang N, Corbett KS, Goldsmith JA, Hsieh CL, Abiona O, Graham BS, McLellan JS (2020) Cryo-EM structure of the 2019-nCoV spike in the prefusion conformation. Science 367:1260-1263. https://doi.org/10.1126/science.abb2507

18. Douglas GC, O’Bryan MK, Hedger MP, Lee DK, Yarski MA, Smith AI, Lew RA (2004) The novel angiotensin-converting enzyme (ACE) homolog, ACE2, is selectively expressed by adult Leydig cells of the testis. Endocrinology 145:4703-4711

19. Verdecchia P, Cavallini C, Spanevello A, Angeli F (2020) The pivotal link between ACE2 deficiency and SARS-CoV-2 infection. Eur J Intern Med. https://doi.org/10.1016/j.ejim.2020.04.037

20. Messerli FH, Siontis GCM, Rexhaj E (2020) COVID-19 and renin angiotensin blockers: current evidence and recommendations. Circulation. https://doi.org/10.1161/CIRCULATIONAHA.120. 047022

21. Kai H, Kai M (2020) Interactions of coronaviruses with ACE2, angiotensin II, and RAS inhibitorslessons from available evidence and insights into COVID-19. Hypertens Res. https://doi.org/10. 1038/s41440-020-0455-8

22. Magrone T, Magrone M, Jirillo E (2020) Focus on receptors for coronaviruses with special reference to angiotensin-converting enzyme 2 as a potential drug target - a perspective. Endocr Metab Immune Disord Drug Targets. https://doi.org/10.2174/1871530320666200427112902

23. Gurwitz D (2020) Angiotensin receptor blockers as tentative SARS-CoV-2 therapeutics. Drug Dev Res. https://doi.org/10.1002/ddr.21656

24. Fang L, Karakiulakis G, Roth M (2020) Are patients with hypertension and diabetes mellitus at increased risk for COVID-19 infection? Lancet Respir Med 8:e21. https://doi.org/10.1016/S22132600(20)30116-8

25. Richardson S, Hirsch JS, Narasimhan M, Crawford JM, McGinn T, Davidson KW, and the Northwell C-RC, Barnaby DP, Becker LB, Chelico JD, Cohen SL, Cookingham J, Coppa K, Diefenbach MA, Dominello AJ, Duer-Hefele J, Falzon L, Gitlin J, Hajizadeh N, Harvin TG, Hirschwerk DA, Kim EJ, Kozel ZM, Marrast LM, Mogavero JN, Osorio GA, Qiu M, Zanos TP (2020) Presenting characteristics, comorbidities, and outcomes among 5700 patients hospitalized with COVID-19 in the New York City Area. JAMA. https://doi.org/10.1001/jama.2020.6775

26. Patel AB, Verma A (2020) COVID-19 and angiotensin-converting enzymeinhibitors and angiotensin receptor blockers: what is the evidence? Jama 323(18):1769-1770

27 Singh AK, Gupta R, Misra A (2020) Comorbidities in COVID-19: outcomes in hypertensive cohort and controversies with renin angiotensin system blockers. Diabetes Metab Syndr 14(4):283287. https://doi.org/10.1016/j.dsx.2020.03.016

28. Guo T, Fan Y, Chen M, Xiaoyan W, Zhang L, He T, Wang H, Wan J, Wang X, Zhibing L (2020) Cardiovascular implications of fatal outcomes of patients with coronavirus disease 2019 (COVID19). JAMA Cardiol 5(7):811. https://doi.org/10.1001/jamacardio.2020.1017 
29. Clerkin KJ, Fried JA, Raikhelkar J, Sayer G, Griffin JM, Masoumi A, Jain SS, Burkhoff D, Kumaraiah D, Rabbani L, Schwartz A, Uriel N (2020) Coronavirus Disease 2019 (COVID-19) and Cardiovascular Disease. Circulation. https://doi.org/10.1161/CIRCULATIONAHA.120.046941

30. Rizzo P, Vieceli Dalla Sega F, Fortini F, Marracino L, Rapezzi C, Ferrari R (2020) COVID-19 in the heart and the lungs: could we "Notch" the inflammatory storm? Basic Res Cardiol 115:31. https://doi.org/10.1007/s00395-020-0791-5

31. Zhou F, Yu T, Du R, Fan G, Liu Y, Liu Z, Xiang J, Wang Y, Song B, Gu X, Guan L, Wei Y, Li H, Wu X, Xu J, Tu S, Zhang Y, Chen H, Cao B (2020) Clinical course and risk factors for mortality of adult inpatients with COVID-19 in Wuhan, China: a retrospective cohort study. Lancet 395:10541062. https://doi.org/10.1016/S0140-6736(20)30566-3

32. Gupta AK, Jneid H, Addison D, Ardehali H, Boehme AK, Borgaonkar S, Boulestreau R, Clerkin K, Delarche N, DeVon HA, Grumbach IM, Gutierrez J, Jones DA, Kapil V, Maniero C, Mentias A, Miller PS, May Ng S, Parekh JD, Sanchez RH, Teodor Sawicki K, A SJMTR, Ann Remme C, London B (2020) Current perspectives on coronavirus 2019 (COVID-19) and cardiovascular disease: a white paper by the JAHA editors. J Am Heart Assoc:e017013. https://doi.org/10.1161/JAHA.120. 017013

33. Guzik TJ, Mohiddin SA, Dimarco A, Patel V, Savvatis K, Marelli-Berg FM, Madhur MS, Tomaszewski M, Maffia P, D’Acquisto F, Nicklin SA, Marian AJ, Nosalski R, Murray EC, Guzik B, Berry C, Touyz RM, Kreutz R, Wang DW, Bhella D, Sagliocco O, Crea F, Thomson EC, McInnes IB (2020) COVID-19 and the cardiovascular system: implications for risk assessment, diagnosis, and treatment options. Cardiovasc Res. https://doi.org/10.1093/cvr/cvaa106

34. Zheng YY, Ma YT, Zhang JY, Xie X (2020) COVID-19 and the cardiovascular system. Nat Rev Cardiol 17:259-260. https://doi.org/10.1038/s41569-020-0360-5

35. Fried JA, Ramasubbu K, Bhatt R, Topkara VK, Clerkin KJ, Horn E, Rabbani L, Brodie D, Jain SS, Kirtane A, Masoumi A, Takeda K, Kumaraiah D, Burkhoff D, Leon M, Schwartz A, Uriel N, Sayer G (2020) The variety of cardiovascular presentations of COVID-19. Circulation. https://doi.org/10. 1161/CIRCULATIONAHA.120.047164

36. Shi S, Qin M, Shen B, Cai Y, Liu T, Yang F, Gong W, Liu X, Liang J, Zhao Q, Huang H, Yang B, Huang C (2020) Association of cardiac injury with mortality in hospitalized patients with COVID19 in Wuhan, China. JAMA Cardiol. https://doi.org/10.1001/jamacardio.2020.0950

37. He J, Wu B, Chen Y, Tang J, Liu Q, Zhou S, Chen C, Qin Q, Huang K, Lv J (2020) Characteristic Electrocardiographic manifestations in patients with COVID-19. Can J Cardiol. https://doi.org/10. 1016/j.cjca.2020.03.028

38. Wang D, Hu B, Hu C, Zhu F, Liu X, Zhang J, Wang B, Xiang H, Cheng Z, Xiong Y, Zhao Y, Li Y, Wang X, Peng Z (2020) Clinical characteristics of 138 hospitalized patients with 2019 novel coronavirus-infected pneumonia in Wuhan, China. JAMA. https://doi.org/10.1001/jama.2020.1585

39. Tang N, Li D, Wang X, Sun Z (2020) Abnormal coagulation parameters are associated with poor prognosis in patients with novel coronavirus pneumonia. J Thromb Haemost 18:844-847. https:// doi.org/10.1111/jth.14768

40. Viner RM, Whittaker E (2020) Kawasaki-like disease: emerging complication during the COVID19 pandemic. Lancet. https://doi.org/10.1016/S0140-6736(20)31129-6

41. Verdoni L, Mazza A, Gervasoni A, Martelli L, Ruggeri M, Ciuffreda M, Bonanomi E, D’Antiga L (2020) An outbreak of severe Kawasaki-like disease at the Italian epicentre of the SARS-CoV-2 epidemic: an observational cohort study. Lancet. https://doi.org/10.1016/S0140-6736(20)31103-X

42. Sellers SA, Hagan RS, Hayden FG, Fischer WA 2nd (2017) The hidden burden of influenza: A review of the extra-pulmonary complications of influenza infection. Influenza Other Respir Viruses 11:372-393. https://doi.org/10.1111/irv.12470

43. Akhmerov A, Marbán E (2020) COVID-19 and the Heart. Circ Res 126:1443-1455. https://doi. org/10.1161/CIRCRESAHA.120.317055

44. Klum M, Urban M, Tigges T, Pielmus AG, Feldheiser A, Schmitt T, Orglmeister R (2020) Wearable cardiorespiratory monitoring employing a multimodal digital patch stethoscope: estimation of ECG, PEP, LVETand Respiration Using a $55 \mathrm{~mm}$ Single-Lead ECG and Phonocardiogram. Sensors (Basel) 20.https://doi.org/10.3390/s20072033

45. Shahshahani A, Zilic Z, Bhadra S (2020) An Ultrasound-based biomedical system for continuous cardiopulmonary monitoring: a single sensor for multiple information. IEEE Trans Biomed Eng 67:268-276. https://doi.org/10.1109/TBME.2019.2912407

46. Taebi A, Solar BE, Bomar AJ, Sandler RH, Mansy HA (2019) Recent advances in seismocardiography. Vibration 2:64-86. https://doi.org/10.3390/vibration2010005 
47. Inan OT, Baran Pouyan M, Javaid AQ, Dowling S, Etemadi M, Dorier A, Heller JA, Bicen AO, Roy S, De Marco T, Klein L (2018) Novel wearable seismocardiography and machine learning algorithms can assess clinical status of heart failure patients. Circ Heart Fail 11:e004313. https://doi.org/10.1161/CIRCHEARTFAILURE.117.004313

48. Kuwabara M, Harada K, Hishiki Y, Kario K (2019) Validation of two watch-type wearable blood pressure monitors according to the ANSI/AAMI/ISO81060-2:2013 guidelines: Omron HEM-6410T-ZM and HEM-6410T-ZL. J Clin Hypertens 21(6):853-858. https://doi.org/10. 1111/jch.13499

49. Lu FS, Nguyen AT, Link N, Santillana M (2020) Estimating the prevalence of COVID-19 in the United States: Three complementary approaches. medRxiv:2020.2004.2018.20070821. https:// doi.org/10.1101/2020.04.18.20070821

50. Blanchard IE, Kozicky R, Dalgarno D, Simms J, Goulder S, Williamson TS, Biesbroek S, Page L, Leaman K, Snozyk S, Redman L, Spackman K, Doig CJ, Lang ES, Lazarenko G (2019) Community paramedic point of care testing: validity and usability of two commercially available devices. BMC Emerg Med 19:30. https://doi.org/10.1186/s12873-019-0243-4

51. Stopyra JP, Snavely AC, Scheidler JF, Smith LM, Nelson RD, Winslow JE, Pomper GJ, Ashburn NP, Hendley NW, Riley RF, Koehler LE, Miller CD, Mahler SA (2020) Point-of-care troponin testing during ambulance transport to detect acute myocardial infarction. Prehosp Emerg Care:1-9. https://doi.org/10.1080/10903127.2020.1721740

52. Cohen IG, Gostin LO, Weitzner DJ (2020) Digital Smartphone Tracking for COVID-19: Public Health and Civil Liberties in Tension. JAMA 323:2371-2372. https://doi.org/10.1001/jama. 2020.8570

53. Galindo Neto NM, Sá GGdM, Barbosa LU, Pereira JdCN, Henriques AHB, Barros LM (2020) Covid-19 and digital technology: Mobile applications available for download in smartphones. Texto \& Contexto - Enfermagem 29

54. Banskota S, Healy M, Goldberg EM (2020) 15 Smartphone apps for older adults to use while in isolation during the COVID-19 pandemic. West J Emerg Med 21:514-525. https://doi.org/10. 5811/westjem.2020.4.47372

55. Wu F, Zhao S, Yu B, Chen YM, Wang W, Song ZG, Hu Y, Tao ZW, Tian JH, Pei YY, Yuan ML, Zhang YL, Dai FH, Liu Y, Wang QM, Zheng JJ, Xu L, Holmes EC, Zhang YZ (2020) A new coronavirus associated with human respiratory disease in China. Nature 579:265-269. https:// doi.org/10.1038/s41586-020-2008-3

56. Zhu N, Zhang D, Wang W, Li X, Yang B, Song J, Zhao X, Huang B, Shi W, Lu R, Niu P, Zhan F, Ma X, Wang D, Xu W, Wu G, Gao GF, Tan W, China Novel Coronavirus I, Research T (2020) A novel coronavirus from patients with pneumonia in China, 2019. N Engl J Med 382:727-733. https://doi.org/10.1056/NEJMoa2001017

57. Restrepo MI, Mortensen EM, Pugh JA, Anzueto A (2006) COPD is associated with increased mortality in patients with community-acquired pneumonia. Eur Respir J 28:346-351. https:// doi.org/10.1183/09031936.06.00131905

58. Toru Ü, Ayada C, Genç O, Sahin S, Arik Ö, Bulut I (2015) Serum levels of RAAS components in COPD. Eur Respir J 46(suppl 59):PA3970. https://doi.org/10.1183/13993003.congress-2015. PA3970

59. Wan Y, Shang J, Graham R, Baric RS, Li F (2020) Receptor recognition by the novel coronavirus from Wuhan: an analysis based on decade-long structural studies of SARS coronavirus. J Virol 94.https://doi.org/10.1128/JVI.00127-20

60. Lippi G, Henry BM (2020) Chronic obstructive pulmonary disease is associated with severe coronavirus disease 2019 (COVID-19). Respir Med. https://doi.org/10.1016/j.rmed.2020. 105941

61. Liu W, Tao ZW, Wang L, Yuan ML, Liu K, Zhou L, Wei S, Deng Y, Liu J, Liu HG, Yang M, $\mathrm{Hu}$ Y (2020) Analysis of factors associated with disease outcomes in hospitalized patients with 2019 novel coronavirus disease. Chin Med J (Engl) 133:1032-1038. https://doi.org/10.1097/ CM9.0000000000000775

62 Zhang JJ, Dong X, Cao YY, Yuan YD, Yang YB, Yan YQ, Akdis CA, Gao YD (2020) Clinical characteristics of 140 patients infected with SARS-CoV-2 in Wuhan, China. Allergy. https://doi. org/10.1111/all.14238

63. Vardavas CI, Nikitara K (2020) COVID-19 and smoking: a systematic review of the evidence. Tob Induc Dis 18:20. https://doi.org/10.18332/tid/119324 
64. Wang W, Xu Y, Gao R, Lu R, Han K, Wu G, Tan W (2020) Detection of SARS-CoV-2 in Different Types of Clinical Specimens. JAMA. https://doi.org/10.1001/jama.2020.3786

65. Xie X, Zhong Z, Zhao W, Zheng C, Wang F, Liu J (2020) Chest CT for typical 2019-nCoV pneumonia: relationship to negative RT-PCR testing. Radiology:200343. https://doi.org/10. 1148/radiol.2020200343

66. Kanne JP, Little BP, Chung JH, Elicker BM, Ketai LH (2020) Essentials for radiologists on COVID-19: an update-Radiology Scientific Expert Panel. Radiology:200527. https://doi.org/10. 1148/radiol.2020200527

67. Huang C, Wang Y, Li X, Ren L, Zhao J, Hu Y, Zhang L, Fan G, Xu J, Gu X, Cheng Z, Yu T, Xia J, Wei Y, Wu W, Xie X, Yin W, Li H, Liu M, Xiao Y, Gao H, Guo L, Xie J, Wang G, Jiang R, Gao Z, Jin Q, Wang J, Cao B (2020) Clinical features of patients infected with 2019 novel coronavirus in Wuhan, China. Lancet 395:497-506. https://doi.org/10.1016/S0140-6736(20)30183-5

68. Ng M-Y, Lee EY, Yang J, Yang F, Li X, Wang H, Lui MM-s, Lo CS-Y, Leung B, Khong P-L, Hui CK-M, Yuen K-y, Kuo MD (2020) Imaging profile of the COVID-19 Infection: radiologic findings and literature review. Radiol Cardiothorac Imaging 2(1):e200034. https://doi.org/10.1148/ryct. 2020200034

69. Wang L, Lin ZQ, Wong A (2020) COVID-Net: a tailored deep convolutional neural network design for detection of COVID-19 cases from chest X-ray images. Sci Rep 10:19549. https://doi.org/10. 1038/s41598-020-76550-Z

70. See KC, Ong V, Tan YL, Sahagun J, Taculod J (2018) Chest radiography versus lung ultrasound for identification of acute respiratory distress syndrome: a retrospective observational study. Crit Care 22:203. https://doi.org/10.1186/s13054-018-2105-y

71. Picano E, Scali MC, Ciampi Q, Lichtenstein D (2018) Lung ultrasound for the cardiologist. JACC Cardiovasc Imaging 11:1692-1705. https://doi.org/10.1016/j.jcmg.2018.06.023

72. Lesur O, Chagnon F, Lebel R, Lepage M (2019) In vivo endomicroscopy of lung injury and repair in ARDS: potential added value to current imaging. J Clin Med 8.https://doi.org/10.3390/jcm80 81197

73. Zhou Y, Fan Q, Cavus O, Zhang X (2018) Lung ultrasound: predictor of acute respiratory distress syndrome in intensive care unit patients. Saudi J Anaesth 12:457-461. https://doi.org/10.4103/sja. SJA_73_18

74. Mojoli F, Bouhemad B, Mongodi S, Lichtenstein D (2019) Lung ultrasound for critically ill patients. Am J Respir Crit Care Med 199:701-714. https://doi.org/10.1164/rccm.201802-0236CI

75. Picano E, Pellikka PA (2016) Ultrasound of extravascular lung water: a new standard for pulmonary congestion. Eur Heart J 37:2097-2104. https://doi.org/10.1093/eurheartj/ehw164

76. Emwas AH, Roy R, McKay RT, Tenori L, Saccenti E, Gowda GAN, Raftery D, Alahmari F, Jaremko L, Jaremko M, Wishart DS (2019) NMR Spectroscopy for metabolomics research. Metabolites 9.https://doi.org/10.3390/metabo9070123

77. Ciaramelli C, Fumagalli M, Viglio S, Bardoni AM, Piloni D, Meloni F, Iadarola P, Airoldi C (2017) (1)H NMR To Evaluate the Metabolome of Bronchoalveolar Lavage Fluid (BALf) in Bronchiolitis Obliterans Syndrome (BOS): toward the development of a new approach for biomarker identification. J Proteome Res 16:1669-1682. https://doi.org/10.1021/acs.jproteome.6b01038

78. Viswan A, Singh C, Rai RK, Azim A, Sinha N, Baronia AK (2017) Metabolomics based predictive biomarker model of ARDS: a systemic measure of clinical hypoxemia. PLoS One 12:e0187545. https://doi.org/10.1371/journal.pone.0187545

79. Tay MZ, Poh CM, Renia L, MacAry PA, Ng LFP (2020) The trinity of COVID-19: immunity, inflammation and intervention. Nat Rev Immunol. https://doi.org/10.1038/s41577-020-0311-8

80. Kurrer MO, Kopf M, Penninger J, Eriksson U (2002) Cytokines that regulate autoimmune myocarditis. Swiss Med Wkly 132:408-413. https://doi.org/10.4414/SMW.2002.10054

81. Xu P, Zhou Q, Xu J (2020) Mechanism of thrombocytopenia in COVID-19 patients. Ann Hematol 99:1205-1208. https://doi.org/10.1007/s00277-020-04019-0

82. Wu C, Chen X, Cai Y, Xia J, Zhou X, Xu S, Huang H, Zhang L, Zhou X, Du C, Zhang Y, Song J, Wang S, Chao Y, Yang Z, Xu J, Zhou X, Chen D, Xiong W, Xu L, Zhou F, Jiang J, Bai C, Zheng J, Song Y (2020) Risk factors associated with acute respiratory distress syndrome and death in patients with coronavirus disease 2019 pneumonia in Wuhan China. JAMA Intern Med. https://doi. org/10.1001/jamainternmed.2020.0994

83. Zaninotto M, Mion MM, Cosma C, Rinaldi D, Plebani M (2020) Presepsin in risk stratification of SARS-CoV-2 patients. Clin Chim Acta 507:161-163. https://doi.org/10.1016/j.cca.2020.04.020 
84. Wu Z, McGoogan JM (2020) Characteristics of and important lessons from the coronavirus disease 2019 (COVID-19) Outbreak in China: summary of a report of 72314 cases from the chinese center for disease control and prevention. JAMA. https://doi.org/10.1001/jama.2020.2648

85. Tisoncik JR, Korth MJ, Simmons CP, Farrar J, Martin TR, Katze MG (2012) Into the eye of the cytokine storm. Microbiol Mol Biol Rev 76:16-32. https://doi.org/10.1128/MMBR.05015-11

86. U.S. Food \& Drug Administration (2020) Spectra optia apheresis system with the Depuro D2000 Letter of Authorization. https://www.fda.gov/media/136834/download. Accessed 24 Aug 2020

87. Massachusetts Institute of Technology (2020) Proteins may halt the severe cytokine storms seen in COVID-19 patients. ScienceDaily. https://www.sciencedaily.com/releases/2020/04/200416135950. htm. Accessed 24 August 2020

88. Jiang X, Coffee M, Bari A, Wang J, Jiang X, Huang J, Shi J, Dai J, Cai J, Zhang T, Wu Z, He G, Huang Y (2020) Towards an Artificial intelligence framework for data-driven prediction of coronavirus clinical severity. Comput Mater Continua 63:537-551

89. Wynants L, Van Calster B, Bonten MMJ, Collins GS, Debray TPA, De Vos M, Haller MC, Heinze G, Moons KGM, Riley RD, Schuit E, Smits LJM, Snell KIE, Steyerberg EW, Wallisch C, van Smeden M (2020) Prediction models for diagnosis and prognosis of covid-19 infection: systematic review and critical appraisal. BMJ 369:m1328. https://doi.org/10.1136/bmj.m1328

90. Ramchand J, Patel SK, Srivastava PM, Farouque O, Burrell LM (2018) Elevated plasma angiotensin converting enzyme 2 activity is an independent predictor of major adverse cardiac events in patients with obstructive coronary artery disease. PLoS One 13:e0198144. https://doi.org/10.1371/journal.pone. 0198144

91. Xiao F, Burns KD (2017) Measurement of Angiotensin converting enzyme 2 activity in biological fluid (ACE2). Methods Mol Biol 1527:101-115. https://doi.org/10.1007/978-1-4939-6625-7_8

92. Xu H, Zhong L, Deng J, Peng J, Dan H, Zeng X, Li T, Chen Q (2020) High expression of ACE2 receptor of 2019-nCoV on the epithelial cells of oral mucosa. Int J Oral Sci 12:8. https://doi.org/10.1038/ s41368-020-0074-x

93. Li WT, Ma J, Shende N, Castaneda G, Chakladar J, Tsai JC, Apostol L, Honda CO, Xu J, Wong LM, Zhang T, Lee A, Gnanasekar A, Honda TK, Kuo SZ, Yu MA, Chang EY, Rajasekaran MR, Ongkeko WM (2020) Using machine learning of clinical data to diagnose COVID-19: a systematic review and meta-analysis. BMC Med Inform Decis Mak 20:247. https://doi.org/10.1186/s12911-020-01266-Z

94. Yang HS, Hou Y, Vasovic LV, Steel PAD, Chadburn A, Racine-Brzostek SE, Velu P, Cushing MM, Loda M, Kaushal R, Zhao Z, Wang F (2020) Routine Laboratory Blood Tests Predict SARS-CoV-2 Infection Using Machine Learning. Clin Chem 66:1396-1404. https://doi.org/10.1093/clinchem/hvaa200

95. Plante TB, Blau AM, Berg AN, Weinberg AS, Jun IC, Tapson VF, Kanigan TS, Adib AB (2020) Development and External validation of a machine learning tool to rule out COVID-19 among adults in the emergency department using routine blood tests: a large, multicenter, real-world study. J Med Internet Res 22:e24048-e24048. https://doi.org/10.2196/24048

96. Brinati D, Campagner A, Ferrari D, Locatelli M, Banfi G, Cabitza F (2020) Detection of COVID-19 infection from routine blood exams with machine learning: a feasibility study. J Med Syst 44:135. https://doi.org/10.1007/s10916-020-01597-4

97. Fernandes FT, de Oliveira TA, Teixeira CE, Batista AFM, Dalla Costa G, Chiavegatto Filho ADP (2021) A multipurpose machine learning approach to predict COVID-19 negative prognosis in Sao Paulo, Brazil. Sci Rep 11:3343. https://doi.org/10.1038/s41598-021-82885-y

98. Chamberlain SD, Singh, I, Ariza, CA, Daitch AL, Philips PB, Dalziel BD (2020) Real-time detection of COVID-19 epicenters within the United States using a network of smart thermometers. medRxiv preprint. https://doi.org/10.1101/2020.04.06.20039909

99. Imran A, Posokhova I, Qureshi HN, Masood U, Riaz MS, Ali K, John CN, Hussain MI, Nabeel M (2020) AI4COVID-19: AI enabled preliminary diagnosis for COVID-19 from cough samples via an app. Inform Med Unlocked 20:100378. https://doi.org/10.1016/j.imu.2020.100378

100. Cai M, Li H, Shen S, Wang Y, Yang Q (2018) Customized design and 3D printing of face seal for an N95 filtering facepiece respirator. J Occup Environ Hyg 15:226-234. https://doi.org/10.1080/15459 624.2017.1411598

101. Bachtiar EO, Erol O, Millrod M, Tao R, Gracias DH, Romer LH, Kang SH (2020) 3D printing and characterization of a soft and biostable elastomer with high flexibility and strength for biomedical applications. J Mech Behav Biomed Mater 104.https://doi.org/10.1016/j.jmbbm.2020.103649

102. Bateman NT, Leach RM (1998) ABC of oxygen. Acute oxygen therapy. BMJ 317:798-801. https:// doi.org/10.1136/bmj.317.7161.798 
103. Italian hospital saves Covid-19 patients lives by 3D printing valves for reanimation devices. 3D Printing Media Network, vol 2020. https://www.3dprintingmedia.network/covid-19-3d-printed-valve-forre animation-device/. Accessed 24 Aug 2020

104. Farkas J (2020) Splitting ventilators to provide titrated support to a large group of patients. EMCrit Project, vol 2020. https://emcrit.org/. Accessed 24 Aug 2020

105. Braveman PA, Cubbin C, Egerter S, Williams DR, Pamuk E (2010) Socioeconomic disparities in health in the United States: what the patterns tell us. Am J Public Health 100 Suppl 1:S186-196. https://doi.org/10.2105/AJPH.2009.166082

106. Chang VW, Lauderdale DS (2009) Fundamental cause theory, technological innovation, and health disparities: the case of cholesterol in the era of statins. J Health Soc Behav 50:245-260. https://doi.org/ $10.1177 / 002214650905000301$

107. Glied S, Lleras-Muney A (2008) Technological innovation and inequality in health. Demography 45:741-761. https://doi.org/10.1353/dem.0.0017

108. Korda RJ, Clements MS, Dixon J (2011) Socioeconomic inequalities in the diffusion of health technology: Uptake of coronary procedures as an example. Soc Sci Med 72:224-229. https://doi.org/10. 1016/j.socscimed.2010.11.002

109. Karwat DMA (2019) Engineering for the people: putting peace, social justice, and environmental protection at the heart of all engineering. In: Frontiers of Engineering: Reports on Leading-Edge Engineering from the 2018 Symposium. Washington (DC). https://doi.org/10.17226/25333

110. Du RH, Liang LR, Yang CQ, Wang W, Cao TZ, Li M, Guo GY, Du J, Zheng CL, Zhu Q, Hu M, Li XY, Peng P, Shi HZ (2020) Predictors of mortality for patients with COVID-19 pneumonia caused by SARS-CoV-2: a prospective cohort study. Eur Respir J 55.https://doi.org/10.1183/13993003. 00524-2020

111. Garg S, Kim L, Whitaker M, O’Halloran A, Cummings C, Holstein R, Prill M, Chai SJ, Kirley PD, Alden NB, Kawasaki B, Yousey-Hindes K, Niccolai L, Anderson EJ, Openo KP, Weigel A, Monroe ML, Ryan P, Henderson J, Kim S, Como-Sabetti K, Lynfield R, Sosin D, Torres S, Muse A, Bennett NM, Billing L, Sutton M, West N, Schaffner W, Talbot HK, Aquino C, George A, Budd A, Brammer L, Langley G, Hall AJ, Fry A (2020) Hospitalization Rates and characteristics of patients hospitalized with laboratory-confirmed coronavirus disease 2019 - COVID-NET, 14 States, March 1-30, 2020. MMWR Morb Mortal Wkly Rep 69:458-464. https://doi.org/10.15585/mmwr.mm6915e3

112. Gold JAW, Wong KK, Szablewski CM, Patel PR, Rossow J, Da Silva J, Natarajan P, Morris SB, Fanfair RN, Rogers-Brown J, Bruce BB, Browning SD, Hernandez-Romieu AC, Furukawa NW, Kang M, Evans ME, Oosmanally N, Tobin-D’Angelo M, Drenzek C, Murphy DJ, Hollberg J, Blum JM, Jansen R, Wright DW, Sewell WM, Owens JD, Lefkove B, Brown FW, Burton DC, Uyeki TM, Bialek SR, Jackson BR (2020) Characteristics and clinical outcomes of adult patients hospitalized with COVID19-Georgia, March 2020. MMWR Morb Mortal Wkly Rep 69:545-550. https://doi.org/10.15585/ mmwr.mm6918e1

113. NYC Department of Health (2020) Age-adjusted rates of lab confirmed COVID-19 non hospitalized cases, estimated non-fatal hospitalized cases, and patients known to have died 100,000 by race/ethnicity group. https://www1.nyc.gov/assets/doh/downloads/pdf/imm/covid-19-deaths-raceethnicity-04162 020-1.pdf. Accessed 24 Aug 2020

114. Yancy CW (2020) COVID-19 and African Americans. JAMA. https://doi.org/10.1001/jama.2020. 6548

115. Leidman E, Duca LM, Omura JD, Proia K, Stephens JW, Sauber-Schatz EK (2021) COVID-19 Trends Among Persons Aged 0-24 Years - United States, March 1-December 12, 2020. MMWR Morb Mortal Wkly Rep 70:88-94. https://doi.org/10.15585/mmwr.mm7003e1

116. Children and COVID-19: State-Level Data Report (2021) Critical Updates on COVID-19. American Academy of Pediatrics and the Children's Hospital Association. https://www.aap.org/en/pages/2019novel-coronavirus-covid-19-infections/children-and-covid-19-state-level-data-report/. Accessed 24 Aug 2020

117. Liguoro I, Pilotto C, Bonanni M, Ferrari ME, Pusiol A, Nocerino A, Vidal E, Cogo P (2020) SARSCOV-2 infection in children and newborns: a systematic review. Eur J Pediatr 179:1029-1046. https:// doi.org/10.1007/s00431-020-03684-7

118. Heald-Sargent T, Muller WJ, Zheng X, Rippe J, Patel AB, Kociolek LK (2020) Age-related differences in nasopharyngeal severe acute respiratory syndrome coronavirus 2 (SARS-CoV-2) levels in patients with mild to moderate coronavirus disease 2019 (COVID-19). JAMA Pediatr 174:902-903. https://doi.org/10.1001/jamapediatrics.2020.3651 
119. MIS-C and COVID-19 (2021) National Center for Immunization and Respiratory Diseases (NCIRD). https://www.cdc.gov/mis-c/index.html. Accessed 24 Aug 2020

120. Feldstein LR, Tenforde MW, Friedman KG, Newhams M, Rose EB, Dapul H, Soma VL, Maddux AB, Mourani PM, Bowens C, Maamari M, Hall MW, Riggs BJ, Giuliano JS Jr, Singh AR, Li S, Kong M, Schuster JE, McLaughlin GE, Schwartz SP, Walker TC, Loftis LL, Hobbs CV, Halasa NB, Doymaz S, Babbitt CJ, Hume JR, Gertz SJ, Irby K, Clouser KN, Cvijanovich NZ, Bradford TT, Smith LS, Heidemann SM, Zackai SP, Wellnitz K, Nofziger RA, Horwitz SM, Carroll RW, Rowan CM, Tarquinio KM, Mack EH, Fitzgerald JC, Coates BM, Jackson AM, Young CC, Son MBF, Patel MM, Newburger JW, Randolph AG, Investigators OC (2021) Characteristics and outcomes of US children and adolescents with multisystem inflammatory syndrome in children (MIS-C) Compared With Severe Acute COVID-19. JAMA 325:1074-1087. https://doi.org/10.1001/jama.2021.2091

Publisher's Note Springer Nature remains neutral with regard to jurisdictional claims in published maps and institutional affiliations.

\section{Authors and Affiliations}

\section{Md Shahnoor Amin ${ }^{1} \cdot$ Marcin Wozniak ${ }^{2,3} \cdot$ Lidija Barbaric $^{1} \cdot$ Shanel Pickard $^{1}$. Rahul S. Yerrabelli ${ }^{1}$. Anton Christensen ${ }^{1}$. Olivia C. Coiado ${ }^{1,4,5}$ (D)}

1 Carle Illinois College of Medicine, University of Illinois At Urbana-Champaign, Champaign, IL 61820, USA

2 Beckman Institute for Advanced Science and Technology, Urbana, IL 61801, USA

3 Department of Medical Laboratory Diagnostics - Biobank, Medical University of Gdansk, Gdansk, Poland

4 Department of Bioengineering, University of Illinois At Urbana-Champaign, Urbana, IL 61801, USA

5 Carle Illinois College of Medicine, 1406 W. Green St, Urbana, IL 61801, USA 